\title{
The Teaching Reform and Practice of National Traditional Sports Elective Course Based on "Combination of Sports and Medicine" - Taking China University of Geosciences (Wuhan) as an Example
}

\author{
Yixi Zhang ${ }^{1}$, Kai $\mathrm{Hu}^{1, *}$ and $\mathrm{Hao} \mathrm{He}^{1}$ \\ ${ }^{1}$ School of Physical Education, China University of Geosciences (Wuhan), 430074 \\ *Corresponding author. Email: hukai@cug.edu.cn
}

\begin{abstract}
This paper analyzed and discussed the teaching reform path of the national traditional sports course in China University of Geosciences (Wuhan) by questionnaires, expert interviews and mathematical statistics. It's worth pointing out that students who took the course had prominent eye health problems, and poor physical exercise effect. Furthermore, they mainly faced the following problems when they carried out physical exercise: lack of knowledge pertaining to scientific exercise, emergency treatment of injury as well as exercise prescription. In this research, the teaching reform plan of "Combination of Sports and Medicine" is mainly manifested as follows: developing targeted teaching and treatment methods, spreading the principle of "treating before disease", teaching scientific ways of exercise, as well as teaching rehabilitation, health care knowledge, and exercise prescriptions, etc. The results indicate that this teaching reform plays a significant role in improving students' physical exercise effect, bolstering their interest in exercise, developing good living habits and so on. In addition, it attaches great importance to the integration of sports knowledge and skills and medical knowledge in college students, and serves as an approach to implementing the basic national policy of "Healthy China".
\end{abstract}

Keywords: combination of medical education; traditional sports; sports teaching; teaching reform

\section{INTRODUCTION}

"Healthy China 2030" blueprint points out that the combination of sports and medical treatment is the technical core of solving the national fitness work and the key to expanding sports science to serve the health field. According to Classic of Internal Medicine, China's earliest classic work on medicine, "the upper physician treats the undiseased, the middle physician treats the desired disease, and the lower physician treats the existing disease." and the "combination of sports and medicine" is the deep integration of sports and medical treatment, i.e., taking physical exercise to prevent the occurrence and development of diseases, and returning to a healthy mode through exercise, which make sports more healthy, effective and medical. According to the online survey report on the health condition of Chinese college students, Chinese college students' physical condition is generally good, but their lifestyles still need to be improved. With poor skin condition, lack of sleep and emotional problems being the main factors troubling the health of college students. To improve the health condition of college students, it is indispensable to raise their health consciousness and attention toward a healthy lifestyle. National traditional programs such as fitness qigong and taijiquan are inextricably intertwined with the theories of Traditional Chinese Medicine, and have both fitness and medical properties. Through external guidance, breathing exercises, and meditation, they can enhance the level of all bodily functions, stimulate the body's inner potential, enhance physical fitness, and improve health, i.e., they have unique effects on disease prevention and treatment. . This study takes China University of Geosciences (Wuhan) (hereinafter referred to as CUG) as an example to explore the teaching reform of "Combination of Sports and Medicine" in the public elective course of national traditional sports, and to understand the physical exercise situation and demands of students based on the collection of relevant data. The questionnaire was conducted among the classes and students concerning the national traditional sports courses, i.e., 8 Taijiquan, 2 fitness qigong, and 4 Changquan classes taught by four teachers. To ensure the quality of the questionnaire design, five experts were invited to test the validity of the questionnaire. The questionnaire design met the requirements, and the content validity was up to the standard. A total of 729 questionnaires were returned, with 719 valid questionnaires, with an efficiency rate of $98.6 \%$.

At the same time, through interviews with professors and experts of national traditional sports, sports medicine and sports physiology in colleges and universities, the author in the paper integrated the opinions and suggestions on the 
teaching reform of "Combination of Sports and Medicine" for this course, and formed a teaching reform plan. In addition to teaching the skills of national traditional sports skills, the course also covers the theory of medical health and health care methods. It is intended to raise students' awareness of health, increase their enthusiasm to participate in physical exercise, promote their physical and mental health, and give full play to their role in health care and fitness, and provide reference for the teaching reform of "Combination of Sports and Medicine" in colleges and universities.

\section{BASIC INFORMATION ON THE PHYSICAL ACTIVITY OF STUDENTS TAKING NATIONAL TRADITIONAL SPORTS COURSES}

\subsection{Sub-health problems among students taking courses are prominent}

Subhealth is a physical state between health and disease, and a long-term subhealth state may cause a variety of diseases or psychological disorders. Among the 719 students surveyed, 492, 395 and 274 students showed sleepiness, general weakness and soreness of waist as well as back pain respectively, and only 77 students did not show any adverse conditions. The main causes of subhealth are improper diet, lack of exercise, irregular work and rest, lack of sleep, mental tension, and psychological stress. Strengthening physical exercise is the main means of regulating subhealth, but it is difficult to improve by physical education classes alone, and students need to make full use of their spare time for physical exercise. The main causes of sub-health include unreasonable diet, lack of exercise, irregular work and rest, lack of sleep, mental stress and great psychological pressure. Strengthening physical exercise is the main means of improving subhealth, but it is difficult to improve by relying solely on physical education class. On the other hand, students need to make full use of their free time to do physical exercise.

\subsection{Lack of knowledge pertaining to scientific exercise, emergency treatment of injury as well as exercise prescription}

The results show that among 719 students, the number of students who did not know and did not know at all about the knowledge related to physical exercise were 540, 535, 620 and 654 respectively (see Table 3 ), which shows that the improper cognition of scientific exercise is the culprit of poor exercise effect. Students' shortage in knowledge about scientific exercise, injury protection and emergency treatment, rehabilitation training and exercise prescription. And they are unfamiliar with the principles and methods of scientific exercise, which reveals that P.E teachers usually neglect to teach this part of knowledge in the P.E curriculum.

Table 1. Statistics on students' common sub-health conditions $(\mathrm{n}=719)$

\begin{tabular}{|c|c|c|}
\hline & Number of people & Percentages \\
\hline Sleepy and easy to sleep & 492 & $68.4 \%$ \\
\hline Full body weakness & 263 & $36.7 \%$ \\
\hline Soreness of waist \&back pain & 274 & $38.1 \%$ \\
\hline Chest tightness and shortness of breath & 168 & $23.4 \%$ \\
\hline Slow-minded & 271 & $37.7 \%$ \\
\hline Diminished memory & 313 & $43.5 \%$ \\
\hline Easily fatigued & 395 & $54.9 \%$ \\
\hline None of the above & 77 & $10.7 \%$ \\
\hline Others & 3 & $1.8 \%$ \\
\hline
\end{tabular}

Table 2. Students' cognition of scientific exercise and basic knowledge of sports medicine ( $\mathrm{n}=719)$

\begin{tabular}{|c|c|c|c|c|c|}
\hline & $\begin{array}{c}\text { Very } \\
\text { knowledgeable }\end{array}$ & $\begin{array}{c}\text { Relatively } \\
\text { familiar }\end{array}$ & $\begin{array}{l}\text { Underst } \\
\text { and }\end{array}$ & $\begin{array}{c}\text { Don't know } \\
\text { much about it. }\end{array}$ & Not at all. \\
\hline Scientific exercise knowledge & 24 & 54 & 101 & 475 & 65 \\
\hline $\begin{array}{l}\text { Emergency treatment of sports } \\
\text { injuries }\end{array}$ & 22 & 59 & 103 & 446 & 89 \\
\hline Rehabilitation exercise & 15 & 27 & 57 & 497 & 123 \\
\hline Exercise prescription & 11 & 21 & 33 & 435 & 219 \\
\hline
\end{tabular}




\subsection{Poor effectiveness of physical exercise}

At present, universities attach great importance to students' physical fitness, as evidenced by the inclusion of physical education results and physical fitness status in the evaluation of merit, awards, graduation, and postgraduate recommendation. However, among the 719 students surveyed, 416, 381, and 280 believe that the previous physical exercise failed to achieve the goals of weight loss, improvement of physical fitness, and strength growth, indicating that the students' exercise was ineffective and the changes were not obvious. The conversation also revealed that most students who choose courses do not like strenuous activities despite caring about their weight.

\section{TEACHING REFORM PLAN AND IMPLEMENTATION OF "COMBINATION OF SPORTS AND MEDICINE" IN NATIONAL TRADITIONAL PHYSICAL EDUCATION}

\subsection{Developing design ideas for teaching reform of "Combination of Sports and Medicine"}

Experts were interviewed on the following topics: the teaching reform concept of "Combination of Sports and Medicine" in National Traditional Sports courses; the integration of knowledge and technology of National Traditional Sports programs with health; the method of how to impart scientific fitness knowledge and skills, and the method of physical fitness exercises, etc. Taking the actual health conditions, exercise effects and needs of students into account, the interviewed experts reached a consensus on the following:

- The core of the "Combination of Sports and Medicine" teaching reform is to carry out the idea that "Sports can effectively promote health";

- Drawing on the results of domestic and foreign research on the "Combination of Sports and Medicine" is beneficial for the integration of the national and the global. The teaching reform plans should be made in terms of teaching philosophy, teaching content, teaching procedures and methods.

- In the teaching reform of "Combination of Sports and Medicine" attached to the national traditional P.E. class, we should tap into the fitness value and principle of national traditional sports, so that it can showcase the advantages of national traditional sports in promoting health and wellness;

- We should abide by people-oriented principle. Moreover, we may as well follow the law of physical and mental development, interests and needs of college students, which can draw students' interest toward national traditional sports and usher into "combination of sports and medicine". On the other hand, it can help students recognize the importance of scientific exercise, master scientific exercise methods, and cultivate the consciousness and habit of scientific training;

- The implementation of the teaching reform should be targeted and student-oriented, which can effectively help students solve their puzzles and doubts during exercise and answer their questions.

\subsection{Teaching reform plan of "Combination of Sports and Medicine” in National Traditional Physical Education}

The teaching reform plan aims to promote the deep integration of sports and medicine and improve the scientific, pertinent, and practical approach to physical education and sports. It follows the laws of sports knowledge learning and cognition of "perceptual cognition-rational generalization-rational cognitionapplication of sports situation". Furthermore, it carries out teaching in a relevant and practical way, which is highlighted as follows: spreading the philosophy of "treating before disease"; enhancing students' awareness of physical exercise and health; imparting scientific ways of exercise as well as knowledge of rehabilitation and health care; teaching exercise prescription to improve the scientific aspect of students' physical exercise.

As Classic of Internal Medicine, China's earliest classic work on medicine, pointed out: the upper physician treats the undiseased, not to treat the already diseased. To put it another way, we had better take corresponding measures to prevent the occurrence and development of diseases, including adapting, regulating the spirit and emotion and keeping the balance between yin and yang. Based on the core concept of "treating before disease", "Combination of Sports and Medicine" is used to prevent the occurrence of disease, enhance physical fitness and improve health.

National traditional sports such as martial arts and fitness qigong inherit the excellent theories and great ideas of Confucianism, Buddhism and Taoism on preserving people's health, which have the functions of strengthening the 上 body and nurturing the mind, and are excellent sports for maintaining physical health, preventing diseases, and promoting health and longevity. While guiding students to learn sports skills, these sports also include the theoretical principles of TCM such as Yin and Yang, Five Elements, Qi and Blood, Body Fluid, Vital Essence and the Meridian system, We try to make students master the principles behind these movements and know how to choose the right ones according to specific situations and strengthen the awareness of physical exercise, so as to achieve the effect of "treating before disease". Scientific exercise methods are of great significance for avoiding sports injuries and improving sports effects. In view of students' specific health conditions and sport's needs, the course incorporates a variety of scientific training methods, carries out lectures 
on health, weight loss and shaping, and scientific exercise, and teaches exercise and professional knowledge health around students' concerns about human physiological structure, food intake, energy metabolism, physical fitness, and sports rehabilitation.

As is often the case, the conditions of shoulder and neck pain, lumbar disc protrusion and knee joint damage are common among students. In addition, students usually spend too much screen time, which exerts an adverse impact their posture. To this end, we formulate prevention and treatment exercises such as stretching exercises for shoulder and neck and lumbar disc. What's more, rehabilitation health care knowledge was assigned to different periods in a planned and step-by-step manner for teaching, so that students could understand the way of joint activities and master scientific and correct posture. For example, static exercises such as standing piles of Tai Chi are arranged for students who are weak and have poor strength quality to improve their thigh muscle strength; self-weight training with no requirements for places and facilities; simple movements, both targeted and fun features. Moreover, high-intensity intermittent training (HIIT), aerobic endurance training, coordinated exercises and other contents will be included in the physical fitness training part of the course.

Exercise prescription is a systematic and personalized exercise program that determines the purpose, form, intensity, time, frequency and precautions of the exerciser according to his age, gender, health status and physical fitness level. The mastery of exercise prescription plays a positive role in the scientific development of personal exercise plans and the enhancement of exercise effects. Taking endurance exercise prescription (jogging, skipping rope) as an example, this study introduced the calculation methods of exercise intensity measurement indexes such as heart rate, oxygen uptake /MET to students, and guided them to choose reasonable exercise intensity, duration and frequency according to the actual situation of students. Formulated exercise prescription (see Figure 1).

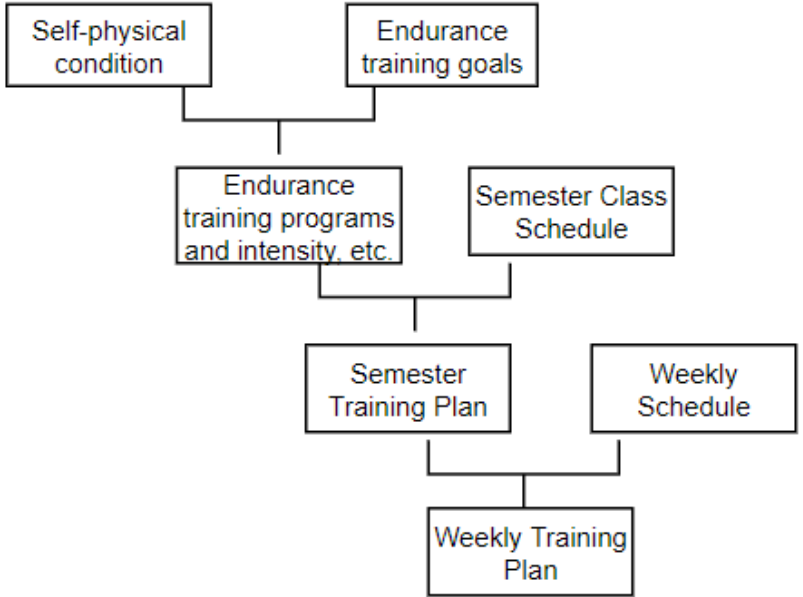

Figure 1. Flow chart for endurance exercise prescription

\subsection{Focusing on the teaching process, and using a variety of teaching organization methods to enhance students' engagement}

The reform of teaching content will inevitably fall into the change of teaching organization methods, comprehensively consider all relevant factors affecting teaching, comprehensively consider from the aspects of integrity, enlightenment, experience, etc. It is suggested that the teaching reforms should adopt teaching methods and organized forms, such as targeted selection of the combination of online class and offline class, and unified teaching and group teaching. (see Table 5)

The education reform has specially set up the WeChat public account of "CUG Combination of Sports and Medicine", and posted more than 20 articles on sports prescription, sports health, fitness and weight loss, traditional health care and sports injury prevention, such as "Healthy China needs such sports prescription" and "Emergency Treatment of Common Sports Injuries", and asked the students study after class according to the schedule of the curriculum. Therefore, a variety of sports teaching methods can make the classroom atmosphere more animated, greatly enhance students' engagement.

Table 3. Teaching methods and organized forms of the teaching reform attached to " Combination of Sports and Medicine"

\begin{tabular}{|c|c|c|c|}
\hline Teaching unit & Teaching content & Teaching methods & Teaching organization \\
\hline \multirow{7}{*}{ Theoretical teaching } & $\begin{array}{c}\text { Exercise prescription, sports } \\
\text { injury prevention and } \\
\text { emergency management, } \\
\text { rehabilitation and health care }\end{array}$ & narration & classes or grades in school \\
\cline { 3 - 4 } & $\begin{array}{c}\text { The philosophy of "treating } \\
\text { before disease"., etc. }\end{array}$ & $\begin{array}{c}\text { narration } \\
\text { discussion method }\end{array}$ & panel \\
\cline { 3 - 4 } & \multicolumn{2}{|c}{ classes or grades in school } \\
\hline
\end{tabular}




\begin{tabular}{|c|c|c|c|}
\hline \multirow{5}{*}{ Skills teaching } & \multirow{2}{*}{ Specialized technical instruction } & narration & classes or grades in school \\
\hline & & framework agreement & classes or grades in school \\
\hline & \multirow{3}{*}{ Specialized technical exercises } & Completeness Act & Individual, group, class \\
\hline & & decomposition & Individual, group, class \\
\hline & & discussion method & panel \\
\hline \multirow{6}{*}{ Physical training } & \multirow{3}{*}{$\begin{array}{c}\text { Self-weight training, static } \\
\text { training, high-intensity interval } \\
\text { training (HIIT) }\end{array}$} & framework agreement & classes or grades in school \\
\hline & & narration & classes or grades in school \\
\hline & & Multiple exercise methods & individuals \\
\hline & \multirow{3}{*}{ Other physical training } & framework agreement & classes or grades in \\
\hline & & narration & classes or grades in school \\
\hline & & Multiple exercise methods & Individual, pair, group \\
\hline \multirow{2}{*}{ appraisal } & Personal Assessment & & individuals \\
\hline & Group assessment & & panel \\
\hline
\end{tabular}

To sum up, the teaching reform plan of "Combination of Sports and Medicine" in the public elective course of national traditional sports mainly embodies three aspects: teaching objectives, teaching contents, teaching procedures and teaching methods (see Table 6); and it mainly manifests itself in enriching the connotation of teaching objectives, correspondingly, increasing teaching contents, expanding teaching arrangements and methods, enhancing the space for integrating in-class and out-of-the-class, and improving the degree of conformity to the teaching goals.

Table 4. Comparison of the elements of the curriculum before and after the teaching reform of "Combination of Sports and Medicine"

\begin{tabular}{|c|c|}
\hline & Pre-reform \\
\hline $\begin{array}{l}\text { Teaching } \\
\text { objectives }\end{array}$ & $\begin{array}{l}\text { The five goals of sports } \\
\text { participation, motor skills, } \\
\text { physical fitness, mental health, } \\
\text { and social adjustment. }\end{array}$ \\
\hline $\begin{array}{l}\text { Teaching } \\
\text { content }\end{array}$ & $\begin{array}{l}\text { Knowledge techniques, physical } \\
\text { training in traditional ethnic } \\
\text { sports }\end{array}$ \\
\hline $\begin{array}{l}\text { Teaching } \\
\text { organization } \\
\text { and methods }\end{array}$ & $\begin{array}{c}\text { Explanations, demonstrations, } \\
\text { breakdown exercises, complete } \\
\text { exercises }\end{array}$ \\
\hline $\begin{array}{l}\text { 4. EFFECTIV } \\
\text { REFORM OF } \\
\text { SPORTS ANL } \\
\text { TO NATION } \\
\text { PHYSICAL E }\end{array}$ & $\begin{array}{l}\text { JESS OF THE TEACHING } \\
\text { COMBINATION OF } \\
\text { IEDICINE" ATTACHED } \\
\text { TRADITIONAL } \\
\text { JCATION CLASS }\end{array}$ \\
\hline
\end{tabular}

Through one year's teaching reform practice, students' interest in sports, health awareness, exercise consciousness and enthusiasm have been significantly improved compared with the past. According to the feedback, $84 \%$ of the students hold the view that the knowledge of scientific exercise, exercise prescription and weight loss actually provide scientific guidance for daily exercise and improve

Post-reform

Sports Participation Objective: To master the techniques and principles of movement of national traditional sports routines and to be able to prepare a feasible personal exercise plan.

Additional exercise skill objectives: mastery of scientific exercise, health, wellness principles and methods, and mastery of exercise prescription.

Expanding physical health goals: knowledge of physical fitness; making sensible healthy and nutritious food choices; developing good behaviors and a healthy lifestyle.

Techniques and principles of national traditional sports programs, theoretical knowledge of health and wellness, principles and methods of physical training, and scientific exercise (sports) prescription.

Technical teaching with lectures, demonstrations, decomposition and complete exercises; theoretical knowledge with lectures, demonstrations, discussion methods, lectures,

online media learning (WeChat public account), etc.; combination of inside and outside the classroom. the effect of physical exercise; $59.5 \%$ of the students mention that the integration of fitness and health principles in the teaching of national traditional sports is conducive to mastering the movements and bolstering the interest in physical exercise; $62 \%$ of the students hold that weight loss, exercise prescription and physical exercise play a good role in their weight loss, shaping, fitness and muscle gain; $56.5 \%$ of students point out that the integration of medical and health knowledge in the classroom helps the development of good living habits.

In the teaching reform course of " Combination of Sports and Medicine", students choosing the class have developed interest and ideas for further learning. They use their spare time to practice, improve their competitive level and participate in various competitions under the guidance of teachers. Ordinary students participated in martial arts and 
Fitness Qigong competitions in Hubei Province and won gold, silver, and bronze medals (awards) more than ten times. These include the second runner-up in the individual event of the general Ba Duan Jin; the first, second, fifth, sixth place in the competition exercise Ba Duan Jin, etc. The first place in the individual traditional boxing (Tai Chi) of the women's group A of martial arts side. Men's Group A has the third place in self-selected fencing, the fourth place in the three-person duo practice, and the second place in traditional boxing (Tongbeiquan).

In the teaching reform of" Combination of Sports and Medicine", we have been exploring and optimizing the teaching contents of national traditional sports. As the course progresses, unfamiliar people have started to appear in the classroom, such as postgraduate students and faculty members, who actively participate in the learning of national traditional sports. In addition, the taijiquan performance by international students and the taijiquan and dragon dance performance by faculty members in the university sports meet also made a lasting impression on students and faculty members.

On top of that, the national traditional sports programs have been gaining traction on campus and the number of beneficiaries has been continuously expanded, which are conducive to the development and promotion of national traditional sports programs.

\section{CONCLUSION}

In the context of the "Healthy China" policy, the teaching reform of the "Combination of Sports and Medicine" in the public elective course of national traditional sports is supported by the characteristics of the national traditional sports, and actively advocates the philosophy of "treating before disease". Additionally, it integrates national traditional sports as well as the ideas and methods of traditional Chinese medicine into physical education. which can further explore and embody the function of "Combination of Sports and Medicine" in a deeper manner. It is a beneficial attempt for the reform of public physical education in colleges and universities.

From the perspective of nation and society, the teaching reform of "Combination of Sports and Medicine" is a conducive way to discover and organize the knowledge and techniques of traditional physical fitness and health care, and absorb the essence of traditional national sports and carry forward the spirit of traditional national culture. It also serves as an approach to implementing the basic national policy of "Healthy China".

As far as the school is concerned, it attaches great importance to the integration of sports knowledge and skills and medical knowledge in college students, which is helpful for college physical education to better implement the idea of "health first".

From the individual's standpoint, it is of paramount importance to promote the concept of "exercise is a good doctor", disseminate the traditional medical philosophy of "treating before disease" and teach the knowledge and skills of "Combination of Sports and Medicine". These measures and approaches will play a substantial and positive role in raising students' awareness of scientific exercise and disease prevention, arousing students' awareness of physical health and interest in exercise, mastering the way of exercise prescription for strengthening physical fitness, and improving the effectiveness of physical exercise.

\section{REFERENCES}

[1]. Li Xueying. "Combination of Sports and Medicine" Is the Core of Technology to Solve the Work of National Fitness [N]. China Sports News, 2016. 11. 02. (001).(In Chinese)

[2]. Liao Yuanpeng, Wang Yu, Hu Yushi, et al. The Combination of Physical Medicine: An Important Way to Build a "Healthy China"[J]. Journal of Chengdu Sports Institute, 2017, 43(1):5-7.(In Chinese)

[3]. Ma Yude. On Traditional Health Care Sports and Physical Education Classes for College Students [J]. Journal of Nanjing Institute of Physical Education, 2006, 20(1):83-85.(In Chinese)

[4]. Yan Pengli. Ninety Percent of the Country's Cities are "Sub-Healthy"[J]. Environmental Economics, 2016(z9):76-76.(In Chinese)

[5]. Geng Yuanqing. The Moderating Effect of Baduanjin on Mental Subhealth [C]. 2012 Nanjing International Chinese Medicine Forum and the Founding Conference of the World Health Promotion Federation. 2012.(In Chinese)

[6]. Wen Zhongyang. Subhealth: Don't Forget to Detoxify the Intestinal Tract for Health Maintenance[J]. Health Care: Health Care World, 2010(8):31-31.(In Chinese)

[7]. Li Shuzhen. "Treating Before Disease" Is Promoted by Both Chinese and Western Medicine[J]. Healthy Living, 2017(3):27-29.(In Chinese)

[8]. Cai Haisheng. Exploration of the Mystery of Shaolin Martial Arts[J]. Zhongzhou Sports: Shaolin and Taiji, 2015(7):10-13.(In Chinese)

[9]. Hu K, Wang Y. An Empirical Study on the Overseas Spread of Martial Arts-Taking the Spread of Martial Arts in Confucius Institute in the United States as an Example[J]. Journal of Shandong Institute of Sports, 2017(5):36-39.(In Chinese)

[10]. Zhang Ruili, Liu Hongjie, Huang Xibin. Research on the Feasibility of "Equipment-Free" Fitness Promotion in Colleges and Universities [J]. Popular Science and Technology, 2014(10):145-146.(In Chinese)

[11]. Wang Zhengzhen, Xu Junhua. Exercise Prescription (second edition) [M]. Beijing: Higher Education Press, 2018.(In Chinese) 